\section{Spinal Cord Regeneration: It's a Matter of Time to Find the Solution}

\author{
Julius July ${ }^{1 *}$ \\ ${ }^{1}$ Department of Neurosurgery, Siloam Lippo Karawaci Hospital, Indonesia
}

It's estimated that more than 15,000 people suffer from spinal cord injury each year in Indonesia, and most of them will die because of the complication. The treatment and rehabilitation for them require lots of fund and in countries like Indonesia will be huge burden for the family. There is very limited access to good rehabilitation facilities or appropriate hospital care for spinal cord injuries; this also contributes to a high mortality rate especially after the cervical cord injury. We believe that more than one third of the world population is still facing the same situation like in Indonesia.

In the research field of neuroscience, we also realize that it's been many years of research trying to look for key factors in spinal cord regeneration. The role of certain gene expression for the axonal regeneration such as GAP-43 [1], CAP-23 [2], etc. in laboratory work has shown few positive results. The balance between the promoting and inhibiting molecules, peptides and antibodies also showed their role. The promoting role of NT-3 [3] is promising for axonal regeneration after axotomy and it also reducing the cell loss after the cord injury. On the other side, myelin could inhibit the regeneration through its molecule such as myelin-associated glycoprotein, nogo, and oligodendrocyte myelin glycoprotein [4]. All these molecules are involved in the receptor nogo-66 [5] and the presence of antibody or peptide inhibitor to nogo receptor have shown its role in axonal regeneration. The other problem that never been solved yet, is the erroneous sprout of the nerve fibers (axon) which will not follow the original fibers map. This sprout sometimes causes more problems to the patients. Realizing this problem, the researchers have tried many methods to drive the appropriate growth of the transected axon. They have tried PVC polymer that filled with Schwann cell to re-attach the two ends of the transected axon and transplantation of the olfactory ensheathing glia (OEG). The understanding of immune privileged in the cord that prevents the regeneration has lead to the implantation of macrophage in the injured cord. All those researches have actually leaded us to a better understanding what really happened to the injured cord. Although there is nothing significant that contribute to the patient long-term functional outcome yet, but we believe that a better understanding of all the pathology process will improve the patient care. There is a role of stem cells also in the line of research interest. Unfortunately, even with the stem cells, the erroneous sprout of axonal regeneration is still an unsolved challenge.

Some evidence also shows that sensory stimulation of locomotion as part of aggressive neuro rehabilitation improves the functional state. The improvement proves the role of distal feedback to the proximal nervous system in the context of appropriate axonal path finding. If in the future we could develop a combination of treatment consisting of specific axonal regeneration with minimal scar formation, minimal cell loss, appropriate axonal path finding, and the optimal acceleration of axonal sprouting, this should be an ideal treatment for the spinal cord injured patients. The use of electrical current or any kind of wave stimulation possibly could drive the sprouting to the appropriate area (region). At least some evidences from peripheral nerve repair shows that the electrical stimulation could be beneficial, and also the existence of acupuncture.

It's only a matter of time for us to find the solution...

\section{References}

1. Kalil K, Skene JH (1986) Elevated Synthesis of an Axonally Transported Protein Correlates with Axon Outgrowth in Normal and Injured Pyramidal Tracts. J Neurosci 6: 2563-2570.

2. Bomze HM, Bulsara KR, Iskandar BJ, Caroni P, Skene JH (2001) Spinal axon regeneration evoked by replacing two growth cone proteins in adult neurons. Nat Neurosci 4: 38-43.

3. Tuszynski MH, Grill R, Jones LL, Brant A, Blesch A, et al. (2003) NT-3 gene delivery elicits growth of chronically injured corticospinal axons and modestly improves functional deficits after chronic scar resection. Exp Neurol 181: 4756.

4. GrandPré T, Nakamura F, Vartanian T, Strittmatter SM (2000) Identification of the Nogo inhibitor of axon regeneration as a reticulon protein. Nature 403: 439-444.

5. Liu BP, Fournier A, GrandPré T, Strittmatter SM (2002) Myelin-associated glycoprotein as a functional ligand for the Nogo-66 receptor. Science 297: 1190-1193. 